\title{
Articles
}

\section{Determination of Buprenorphine in Raw Material and Pharmaceutical Products Using Ion-pair Formation}

\author{
Massoud Amanlou. ${ }^{\dagger}$ Peghah Khosravian, Effat Souri, Orkideh Ghorban Dadrass, ${ }^{\dagger}$ \\ Rasoul Dinarvand, ${ }^{+}$Mohammad Massoud Alimorad,,+ and Hamid Akbari ${ }^{+}$ \\ Department of Medicinal Chemistry, Factlty of Pharmacy and Pharmaceutical Sciences Research Center; \\ Medical Sciences/University of Tehran 14155-6451, Iran. "E-mail: amanlou@isina.tams.ac.ir \\ 'Department of Pharmaceutical Chemistry, Factlty of Pharmacy, Azad University, Tehran, Iran \\ *Deparment of Phamacetrics, Factlty of Pharmacy, Medical Sciences/University of Tehran, Tehran 14155-6451, Iran \\ Received Augtist 31, 2006
}

\begin{abstract}
A simple and sensitive extractive spectrophotometric method has been described for the determination of buprenorphine either in raw material or in pharmaceutical formulations. The developed method is based on the formation of a colored ion-pair complex $(1: 1 \mathrm{drug} / \mathrm{dye})$ of buprenorphine and bromocresol green (BCG) in buffer $\mathrm{pH} 3$ and extracting in chloroform. The extracted complex shows absorbance maxima at $415 \mathrm{~nm}$. Beer's law is obeyed in the concentration range of $1.32-100.81 \mu \mathrm{g} \mathrm{mL}^{-1}$. The proposed method has been applied successfully for the determination of drug in commercial sublingual tablets and injectable dosage form. No significant interference was observed from the excipients commonly used as pharmaceutical aids with the assay procedure.
\end{abstract}

Key Words : Spectrophotometry, Buprenorphine, Bromocresol green, Ion-pair complex

\section{Introduction}

Buprenorphine (BUP) is a potent semi-synthetic opiate analgesic with a potency of 20-40 times higher than that of morphine. ${ }^{1}$ As an analgesic, it has been used successfully by intramuscular, intravenous or sublingual routes for the treatment of moderate to severe pain as well as chronic pain. ${ }^{2}$ Like other opiates it can be abused. ${ }^{3}$ It has been suspected in the doping of racehorses. ${ }^{4}$ Therefore, the matrices in which BUP could be determined are very different, especially in pharmaceuticals and biological samples.

The analysis of BUP in biological samples is abundantly described in the literature. Chromatographic techniques have been widely employed since they are powerful separation techniques. These methods based on liquid chromatography with $\mathrm{UV}^{5-7}$ fluorescence, ${ }^{8}$ electrochemical ${ }^{9}$ and mass spectrometric detection have been applied to the analysis of BUP in plasma or serum, whole blood, urine, feces, cadaveric tissues or hair. ${ }^{10} \mathrm{Gas}$ chromatography $(\mathrm{GC})$ associated with mass, ${ }^{11}$ electron capture detector ${ }^{12}$ was also used to determine low concentrations of BUP biological samples. The immunoassay techniques such as fluoroimmunoassay ${ }^{13}$ and radioimmunoassay ${ }^{14}$ have been developed for the determination of this drug in biological samples. TLC was used for determination of BUP in urine ${ }^{15}$ and pharmaceutical preparations. ${ }^{16}$

Although many analytic methods were reported to analyze BUP in biological fluids, none of these methods was suitable for the routine analysis of BUP in pharmaceutical prepa- ration. Extractive spectrophotometric procedures are popular for their sensitivity in the assay of drugs and, therefore, ionpair extractive spectrophotometry has received considerable attention for the quantitative determination of many phannaceutical compounds, ${ }^{17-20}$ and different alkaloids. ${ }^{21}{ }^{22}$

We, therefore, developed a simple and rapid spectrophotometric method with a one-step extraction procedure for determination of BUP in pharmaceutical preparations. This method has been successfully applied to formulation studies of BUP.

\section{Experimental Section}

Materials and Reagents. Buprenorphine $\mathrm{HCl}$ (BUP·HCl) was obtained from Diosynth (Apeldoorn, The Netherlands). All chemicals were of analytical reagent grade of Merck (Germany) unless otherwise specified. Doubly distilled water was used to prepare all solutions. Freshly prepared solutions were always employed. USP standard buffer solution $(\mathrm{pH}=$ 3) was prepared by diluting $50 \mathrm{~mL}$ of $0.2 \mathrm{M}$ potassium hydrogen phthalate and $22.3 \mathrm{~mL}$ of $0.2 \mathrm{M} \mathrm{HCl}$ to $200 \mathrm{~mL}$ with distilled water. ${ }^{23}$ Bromocresol green solution (BCG, $1 \times$ $10^{-4} \mathrm{M}$ ) was prepared in distilled water. Pharmaceutical grade of sodium alginate $(\mathrm{MW}=10000-60000)$, maize starch $(\mathrm{MW}=50000-16000)$ and cellulose $(\mathrm{MW}=243000)$ were kindly donated by Soha Phannaceutical Co (Tehran, Iran).

Tablets containing 0.4,2 and $8 \mathrm{mg}$ active material were supplied from local stores. The inactive ingredient in injec- 
tion dosage form is glucose and in the lablets are lactose, mannitol, maize starch, povidone K30, magnesium stearate, citric acid and sodium citrale.

Apparatus. A Shimadzu UV-160A, UV-VIS spectrophotometer (Japan) with $1 \mathrm{~cm}$ quarty cells was used for all absorbance measurements. The $\mathrm{pH}$ value of all buffers were adjusted using a Metrohm $692 \mathrm{pH}$ meter.

Standard Solution of the Drug. A slock standard solulion of BUP. $\mathrm{HCl}\left(1 \times 10^{3} \mathrm{M}\right)$ was prepared by dissolving BUP.HCl in doubly distilled water. Working standard solutions were then prepared by suitable dilution of the stock standard solution with water.

Recommended Procedure. Into a series of $100 \mathrm{~mL}$ separating funnels, $10 \mathrm{mI}$. of buffer solution of $\mathrm{pH} 3.0$ and $20 \mathrm{mI}$. of BCG were placed. An appropriate volume of $10^{\prime}$ $M$ standard drug solution $(0.25-20 \mathrm{~mL})$ was added to each funnel and mixed well. The funnels were shaken vigorously with $2 \times 5 \mathrm{mI}$. chloroform for $2 \mathrm{~min}$, and then allowed to stand for elear separation of the two phases. The separated organic phase was transfered to a $50 \mathrm{~mL}$, beaker, dricd over anhydrous sodium chloride, and transferred to a $10 \mathrm{~mL}$. volumetric llask. Then the combined extract was made up to the mark with chloroform and mixed well. The absorbance of the organic phase was measured at 415 nm against a reagent blank similarly prepared. The standard calibration curve was prepared to calculate the amount of the analyte drug in unknown samples.

Procedure for the Dosage Forms. Twenty tablets were weighed and ground to a fine powder using a pestle and a mortar. The average weight of a tablet was calculated. An accuralely weighed portion of the powder, equivatent to 4 mg of BUUP. HCl, was transferred into a $100 \mathrm{~mL}$. volumetric flask. The volume was made up to the mark with water, shaken well, and filtered through an ordinary filter paper. Convenient aliquots from this solution were laken for the determination of BUP. $200, \mu \mathbf{L}$ of BUP.HCI injection was used for determination of BUSP without any dilution.

\section{Results and Discussion}

Spectral Claracteristics. Absorption spectra of the yellow color BUP-BCG ion-pair complex is shown in Figure 1 with a maximum absorbance $\left(\lambda_{\max }\right)$ at 415 nm. The colorless blanks have practically negligible absorbance.

Reaction Meclianism. Anionic dyes such as BCG forms

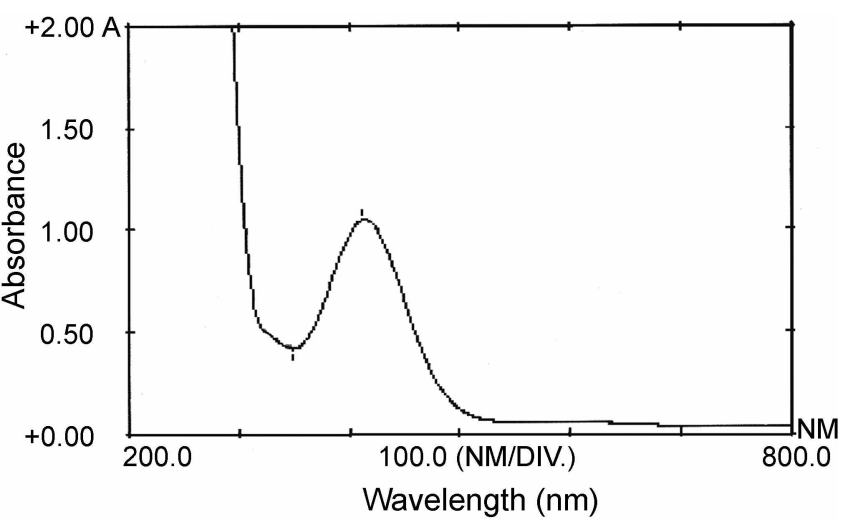

Figure 1. Absorption spectra of BUP-BCG ion-pair complex exIracled into chlorolorm: $B U \mathrm{JP}=60 \mu \mathrm{g} \mathrm{mL} \mathrm{m}^{-1}+20 \mathrm{~mL}$. of $10^{-4} \mathrm{M}$ of $B C G+10 \mathrm{~mL}$ of Potassium hydrogen phthalate-] ICl buffer pl] 3 .

ion-pair complex with the positively charged drugs. The drug-dye stoichiometric ratios as calculated by the continucous variation and mole-ratio methods are found to be $1: 1$. Tach drug-dye complex, with two oppositely charged ions, behaves as a single unit held together by an electrostatic force of attraction (Scheme 1).

Optimization of Variables and Method Development. A number of preliminary experiments established optimum conditions necessary for rapid and quantitalive formation of colored ion-pair complex to achicve the maximum stability and sensilivity. Oplimum condilion was fixed by varying one parameter at a time while kecping other parameters constant and observing its effect on the absorbance at 415 nกา.

Effect of $\mathrm{pH}$. The influence of $\mathrm{pH}$ of buffer solution on the development and stability of the color using different buffer systems such as phthalate, potassium hydrogen phthalate, phosphate and acetate buffers were tested in this study. Polassium hydrogen phthalate-HCI buffer was the buffer of choice, which did not interfere and gave the highest sensitivity for complex formation and extraction. Different $\mathrm{pH}$ (1-6) was tested and the absorbance reading of the BUPBCG ion-pair was examined (Fig. 2). The maximum color intensity was observed in the $\mathrm{pH}$ range of 2.5-3.5 (Fig. 2) and therefore $10 \mathrm{~mL}$ of $\mathrm{pH} 3$ buffer solution, where maximum absorbance were achieved, was used throughout the experiment.

Selecting of the Extracting Solvents. The effect of the

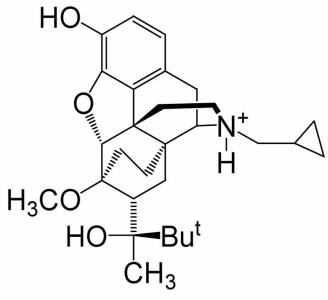

Protonated buprenorphine<smiles>CC1=C(Br)C(=O)C(Br)=CC1=C(c1ccccc1S(=O)(=O)[O-])c1cc(Br)c(O)c(Br)c1C</smiles>

Anion bromocresol green

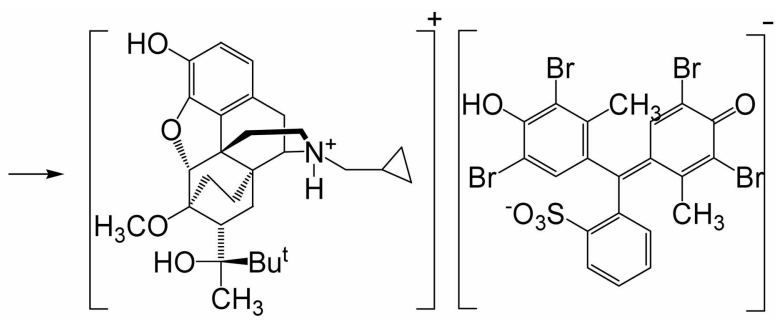

Buprenorphine-bromocresol green complex

Scheme 1. Structure of analyte and formed ion pairs. 


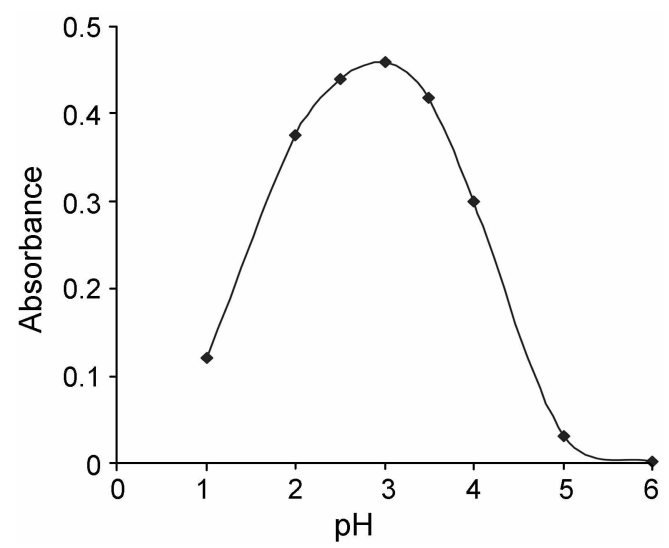

Figure 2. Effect of pH Potassium hydrogen phthalate-[ICI buffer solution on the absorbance of BUP $\left(25 \mu \mathrm{g} \mathrm{mL}^{-1}\right)$-BCG $\left(20 \times 10^{-1}\right.$ M) ion-pair complex.

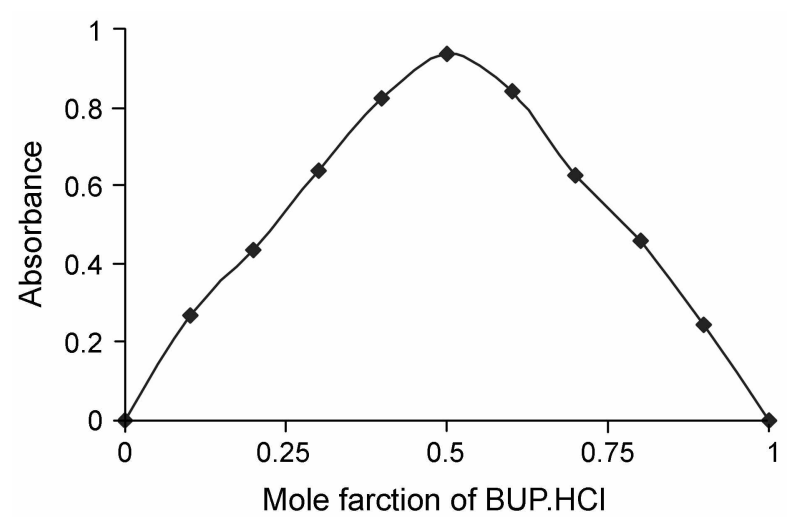

Figure 3. Job's method of continues variation plot for ion-pair complex of BUP.11Cl by BCG in chloroform at $415 \mathrm{~mm}$.

extracting solvent on the ion-pair complex was examined. Chloroform was preferred to other solvents (carbon telrachloride, dichloromethane, and ether) because of its slightly higher efficiency on color intensity, selective extraction of the BUP-BCG complex from the aqueous phase and obtained highest absorbance with chloroform.

Composition of Ion-pair Complexes. The composition of the ion-pair complex was established by Job's method of continuous variations using variable dye and $\mathrm{BUP} \cdot \mathrm{HCl}$ concentrations. The results indicated that $1: 1$ (drug : dye) ion-pair is formed through the electrostatic attraction between the positive protonated drug and the anion of dye (Fig. 3). The extraction equilibrium can be represented as follows:

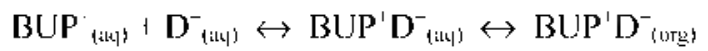

where $\mathrm{BUP}^{-}$and $\mathrm{D}^{-}$represent the protonated $\mathrm{BUP} \cdot \mathrm{HCl}$ and the anion of the dye, respectively. The subscript (aq) and (org) refer to the aqueous and organic phases. Also, the mole-ratio method showed the formation of $1: 2$ ion-pair (Fig. 4). Shape of the resulting curve indicate that the ionpairs are labile. Consequently, a large excess of reagent must always be used to enhance the formation of the complex. A volume of $20 \mathrm{~mL}$ of $\mathrm{BCG}$ solution $\left(10^{-4} \mathrm{M}\right)$ was found to be

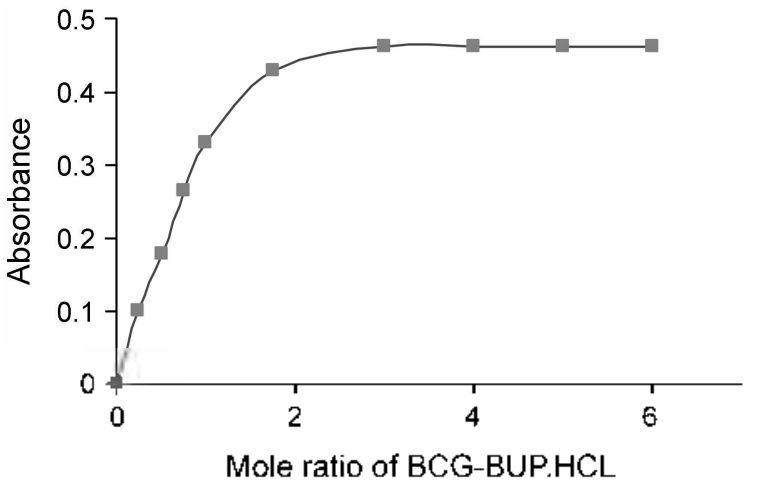

Figure 4. The effect of $\mathrm{BCG}$ concentration on color intensity and extraction efficacy of BUP-BCG ion-pair complex by Mole-ratio $\operatorname{mehod}\left(\mathrm{I} \mathrm{U} \mathrm{JP} \cdot \mathrm{ICl}=50 \mu \mathrm{g} \mathrm{mL}{ }^{1}\right.$ and $\left.\mathrm{I} 3 \mathrm{CG} 10^{-4} \mathrm{M}\right)$.

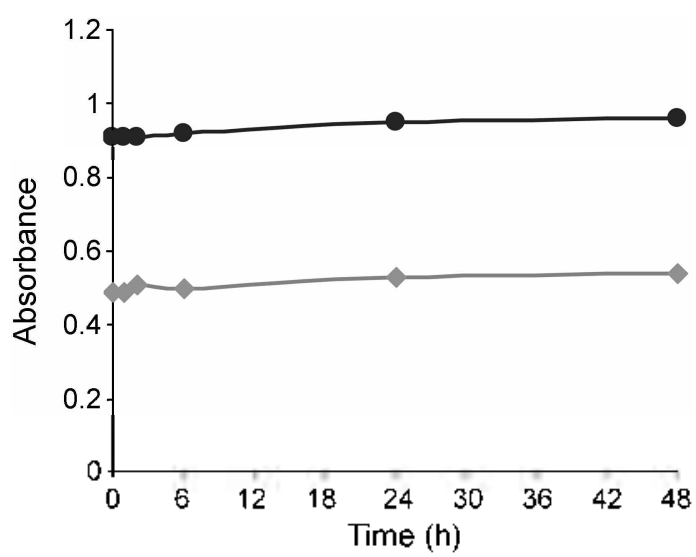

Figure 5. Stability of color complex of 13UP-BCCi in chloroform a1 different concentration of BUP.llCl $\bullet 25 \mu \mathrm{g} \mathrm{mL}^{-1}$ and $\bullet 50 \mu \mathrm{g}$ $\mathrm{mL}{ }^{\prime}$ ).

optimal for complete complexation.

Solution and Colored Complex Stability. The solution stability of the BUP and its tablet solutions was monitored by keeping the solutions at room temperature $\left(25 \pm 1^{\prime \prime} \mathrm{C}\right)$ under darkness for several days and then recording the absorption spectra of the solutions and also by performing TLC analysis. There was no change in the absorption spectra and amount of reference and sample solutions for at least seven days determined by proposed method. The colored ionpair complex was stable for at least $48 \mathrm{~h}$ at $25^{\circ} \mathrm{C}$ (Fig. 5).

Alsalytical Data. Under the optimized experimental condition, calibration curve was constructed by plotting the absorbance at $\lambda_{\text {max }}$ against the concentration of BUP. Beer's law was obeyed in the concentration range 1.32-100.81

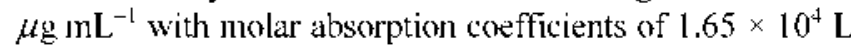
mol ' $\mathrm{cm}^{-1}$. Regression analysis of the Beer's law plots at $\lambda_{\max }$ reveals a good correlation $\left(\mathrm{R}^{2}=0.9995\right)$. The graph show negligible intercept and were described by the regression equation, $y=0.0175 C+0.0376$ (where $y$ is the absorbance of $1 \mathrm{~cm}$ layer, 0.0175 is the slope, 0.0376 is the intercept and $C$ is the concentration of the measured solution in $\mu \mathrm{g} \mathrm{mL} \mathrm{m}^{-1}$ ) obtained by the least-squares method. The high molar absorptivities of the resulting colored complexes 
Table 1. Evaluation of accuracy and precision for the proposed method

\begin{tabular}{cccc}
\hline $\begin{array}{c}\text { Amount taken } \\
\mu \mathrm{g} \mathrm{mL}^{-1}\end{array}$ & $\begin{array}{c}\text { Recovery } \\
\%\end{array}$ & $\begin{array}{c}\mathrm{RSD}^{a} \\
\%\end{array}$ & $\begin{array}{c}\text { RE } \\
\%\end{array}$ \\
\hline 3 & 101.83 & 1.25 & +1.83 \\
10 & 97.10 & 3.60 & -2.90 \\
50 & 99.50 & 0.97 & -0.50 \\
\hline
\end{tabular}

"Average of five determinations

Table 2. Determination of BUT. $\mathrm{HCl}$ in pharmaceutical preparations

\begin{tabular}{cccc}
\hline \multirow{2}{*}{$\begin{array}{c}\text { Dnig trade } \\
\text { name }\end{array}$} & $\begin{array}{c}\text { Label claim } \\
(\mathrm{mg})\end{array}$ & \multicolumn{2}{c}{ \% Recovery of BUP $\pm \% \mathrm{RSD}^{a}$} \\
\cline { 3 - 4 } Temgesic Tablet & 0.4 & $0.39 \pm 2.50$ & $0.39 \pm 2.11$ \\
& 2 & $2.01 \pm 2.61$ & $1.98 \pm 1.97$ \\
& 8 & $7.98 \pm 0.39$ & $8.02 \pm 0.44$ \\
Temgesic Injection & 0.3 & $0.31 \pm 2.12$ & $0.29 \pm 2.39$ \\
\hline
\end{tabular}

"Average of five determinations. ${ }^{\circ}$ Ref. 23 (Non-aqueous litration)

indicate the high sensitivity of the methods.

Method Validation. Samples of pure BUP.HCl at four different concentrations were prepared and tested using the proposed procedures in five replicates. The complete set of validation assays was performed. The results obtained are given in Table 1 . The accuracy of the method is indicated by the good recovery $(97.1-101.83 \%$ ), and the precision is supported by the low relative standard deviation $<3.6 \%$.

Tablets and Injection Analysis. The proposed method was successfully applied to the determination of BUP in commercial sublingual tablets and injection form. The applicability of the proposed methods for the assay of BUP in formulations was examined by analyzing various formulations and the results are tabulated in Table 2. Five replicates determinations were made and satisfactory results were obtained for drug and were in a good agreement with the label claims (Table 2). A USP non-aqueous titration method was employed as a comparison to evaluate the validity of the proposed method. The comparison was performed between BUP-BCG ion-pair formation method and reference method (Table 2) in pharmaceutical preparations. The results were compared by the Wilcoxon test and there was no significant difference between the methods at $P$ $<0.05$. The results were reproducible with low RSD values. The average percent recoveries obtained were quantitative (99.5-99.75\%), indicating good accuracy of method. The results of analysis of the commercial tablets and the recovery study of drug suggested that there is no interference in the analysis from the commonly used additives and excipients in pharnaceutical dosage forms of buprenorphine such as glucose, dextrose, lactose, mannitol, maize starch, povidone $\mathrm{K} 30$, magnesium stearate, citric acid and sodium citrate, sodium alginate, and cellulose (Table 3 ).

The maximum color development of BUP-BCG ion-pair complex formation completed immediately after all reagents were added. No heating or standing was needed. The reliability of the method was established by parallel determination
Table 3. Determination of BUT. $\mathrm{HCl}^{t}$ in presence of excipient

\begin{tabular}{lcr}
\hline Material & $\begin{array}{c}\text { Amount } \\
(\mathrm{mg})\end{array}$ & $\begin{array}{c}\text { \% Recovery } \\
\text { BUP } \pm \% \text { RSD }\end{array}$ \\
\hline Glucose & 20 & $99.51 \pm 3.22$ \\
Dextrose & 20 & $98.93 \pm 1.24$ \\
Lactose & 20 & $99.37 \pm 1.33$ \\
Manitol & 20 & $99.31 \pm 2.31$ \\
Maize starch & 20 & $101.00 \pm 0.59$ \\
Povidone K30 & 20 & $98.33 \pm 1.86$ \\
Magnesium stearate & 10 & $99.40 \pm 1.43$ \\
Citric acid and sodium citrate & 10 & $96.88 \pm 2.46$ \\
Sodium alginate & 10 & $99.10 \pm 1.05$ \\
Cellulose & 10 & $99.30 \pm 0.48$ \\
\hline
\end{tabular}

${ }^{5} 50 \mu \mathrm{g} \mathrm{mL} \mathrm{m}^{-1}$ of BUP.IICl taken. "average of five determinations

against the official USP method (non-aqueous titration). ${ }^{23}$ The present method is not time-consuming procedure such as the standard addition method and there is no need for any expensive equipment. These methods do not involve procedural steps; take more operator time and expertise like HPLC and other methods. On the other hand, in terms of simplicity rapidity, sensitivity and expense, the method could be considered superior in comparison with the previously reported methods, especially with those based on chromatography, ${ }^{5-9}$ and the official USP method. ${ }^{23}$ The proposed methods are simple and rapid with reasonable precision and accuracy when compared to other reported methods. The wide applicability of the described procedure for routine quality control is well established by the assay of BUP in pure form, as well as in pharmaceutical preparations.

A significant advantage of the extractive spectrophotometric method is that it can be applied for the determination of individual compounds in a multi component mixture. Unlike the gas chromatographic and HPLC procedures, the instrument is simple and is not of high cost. The importance lies in the chemical reactions upon which the procedures are based rather than upon the sophistication of the instrument. This aspect of spectrophotometric analysis is of major interest in analytical pharmacy since it offers distinct possibility in the assay of a particular component in complex dosage formulations. The reagents utilized in the proposed methods are cheaper, readily available and the procedures do not involve any critical reaction conditions or tedious sample preparation. The method is unaffected by slight variations in experimental conditions such as $\mathrm{pH}$, reagent concentration or temperature.

\section{Conclusions}

In the present study, the ion-pair formation method can be easily applied to the determination of BUP in raw material and in pharmaceutical dosage forms. The proposed method is simple, rapid and has good sensitivity and accuracy to penmit detemmination of low concentration even down to $1.32 \mu \mathrm{g} \mathrm{mL}^{-1}$. The perfornance of the proposed method has been compared with other existing methods. It has been 
found that the proposed method has the following advantages: (i) more rapid and easy to perform analysis compared to non-aqueous titration (the official USP method); (ii) low cost compared to GC, HPLC and immunoassay techniques. These advantages encouraged the application of the proposed method in routine quality control of burenorphine in raw material samples and pharnaceutical preparations in pharmaceutical laboratories.

Acknowledgment. This study was supported by a grant from the Research Council of Tehran University of Medical Sciences.

\section{References}

1. Heel, R. C.; Brogden, R. N.; Speight, T. M.; Avery, G S. Drrgs $1979,17,81$

2. Hoskin, P. J.; Hanks, G. W. Drugs 1991, 30, 326.

3. Strang, J. Lancet 1985, 8457, 725 .

4. Debrabandere, L.; Van Boven, M.; Laruelle, L.; Daenens, P. Antal. Chim. Acta 1993, 275, 295.

5. Tebbell, I. R. J. Chromatogr: $1985,347,4 \mathrm{II}$.

6. Hacketl, L. P.; Dusci, L. J.; Ileth, K. F. J. Chromatogr: 1986, 374, 400.

7. Lagrange, F.; Pehourcq, F.; Baumevieille, M.; Begaud, B. $J$. Pharm. Biomed. Anal. 1998, 16, 1295.

8. Ho, S. T.; Wang, J. J.; Ho, W.; Hu, O. Y. P. J. Chromatogr: 1991,
570,339 .

9. Debrabandere, L.; Van Boven, M.; Daenens, P. J. Chromatogr. $1991,564,557$.

10. Tracqui, A.; Kintz, P.; Mangin, P. J. Forensic Sci. 1997, 42, 111.

11. Vincent, F.; Besssard, J.; Vacheron, J.; Mallaret, M.; Bessard, G Anal. Toxicol. 1999, 23,270.

12. Everhart, E. T.; Cheung, P.; Shwonek, P.; Zabel, K.; Tisdale, E. C.; Jacob, P.; Mendelson, J.; Jones, R. T. Clin. Chem. 1997, 43, 2292.

13. Debrabandere, L.; Van Boven, M.; Daenens, P. J. Forensic Sci. $1995,40,250$

14. Debrabandere, L.; Van Boven, M.; Laruelle, L.; Daenens, P. Anal. Chim, Acta 1993, 275, 295.

15. Alemany, G.; Gamundi, A.; Rossello, C.; Nicolau, M. C. Bioned. Chromatogr 1996. 10, 146.

16. Chandrashekhar, T. G; Rao, P. S. N.; Vyas, S. K.; Dutl, C. J. Planar Chromatogr: Mod. TLC. 1994, 7, 294.

17. Rahman, N.; Hejaz-Azmi, \$. N. J. Pharm. Biomed. Anal. 2000, $24,33$.

18. Silva, N.; Schapoval, E. E. S. J. Pharm. Biomed. Anal. 2002, 29 , 749.

19. Pérez-Ruiz, T.; Martinez-Lozano, C.; Tomás, V.; Sanz, A.; Sauquillo, E. J. Pharm. Biomed. Anal, 2001, 26,609.

20. Basavaiah, K.; Charan, V. S. IL Famaco 2002, 57,9.

21. Maghsoudi, H.; Fawzi, A. J. Pharm. Sci, 1978, 67, 32.

22. Farsam, H.; Yahya-saeb, H. H.; Fawzy, A. Int. J. Pharm 1981, 7. 343.

23. The United States Pharmacoepia 28. United States Pharmacoepial Convention; Rockville, MD, 2003; p 295. 